\title{
Drawing out classroom social climate: The use of participant-produced drawings in research on psychosocial classroom learning environment in the context of school mathematics
}

\author{
Ana Kuzle ${ }^{1}$ and Dubravka Glasnović Gracin ${ }^{2}$ \\ ${ }^{1}$ University of Potsdam, Germany \\ ${ }^{2}$ University of Zagreb, Croatia
}

Over the last twenty years, visual methods in childhood research have become more mainstream across social science research. Through this paradigm shift, children became active agents in the research process. Participant-produced drawings in particular allow a constructive process of thinking in action, rather than seeing drawings as simple representations of the participants' worldviews. In this paper, we use participant-produced drawings as a window into students' perceptions of the mathematics classroom learning milieu from a social perspective. The goals of this report are threefold: (1) to conceptualize the complex and multifaceted construct of classroom social climate from the standpoint of primary grade students by using a qualitative research approach (i.e., participantproduced drawings), (2) to evaluate the extent to which participant-produced drawings can be used when researching the construct of classroom social climate, and (3) to provide two analytical tools that can be used in qualitative inquiry on classroom social climate in different mathematics lessons. To conclude, versatile recommendations for theory and practice are discussed regarding the employed methodology (i.e., participant-produced drawings as a visual research method) as well as some possible future directions.

Keywords: Classroom social climate, analytical tool, participant-produced drawings, primary education, mathematics

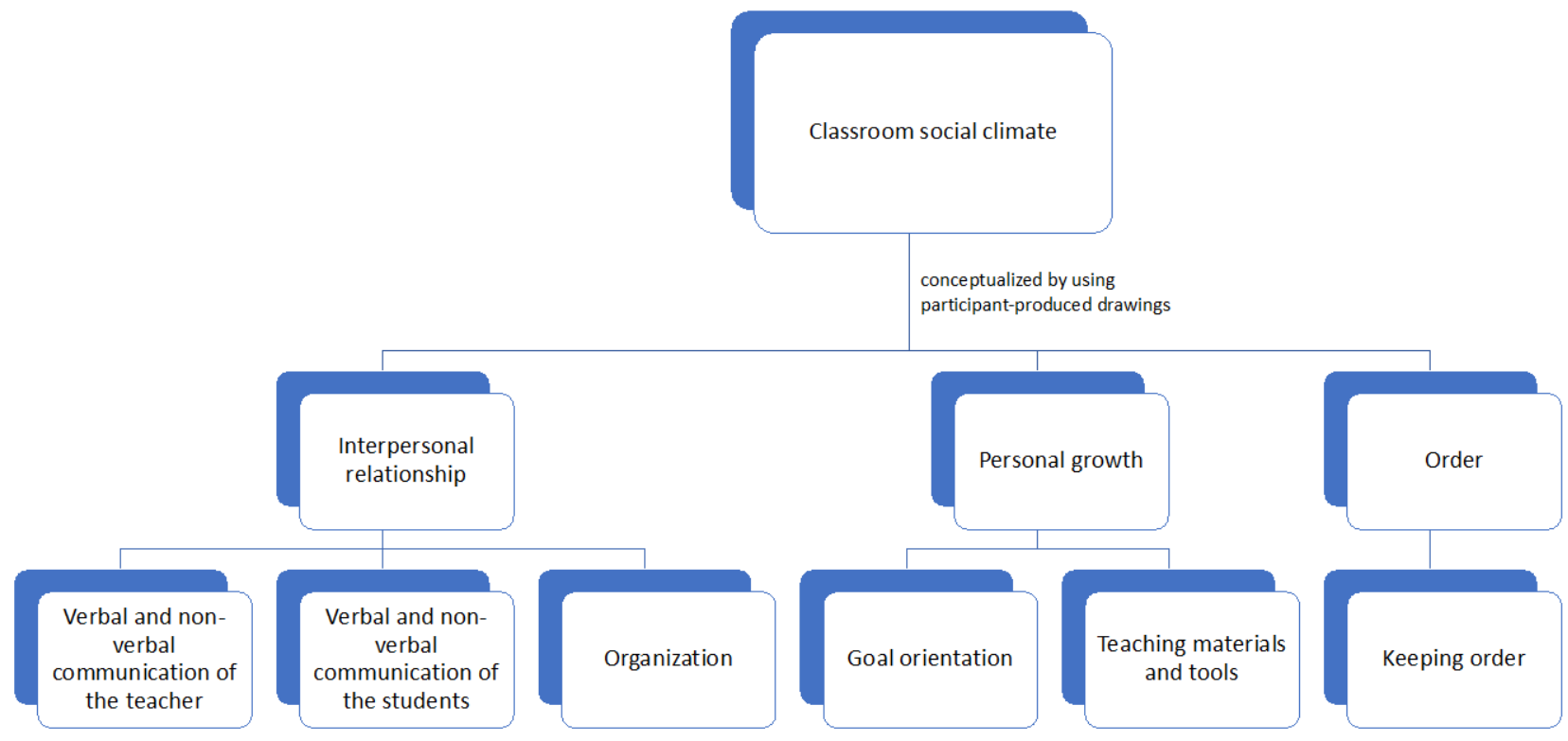


The classroom is a significant social environment in the multifaceted development of children. It shapes students' essential perceptions, and it allows each child to acquire new concepts and procedures (Ahtee et al., 2016). During their time at elementary school, students spend an average of 20-30 hours a week in the classroom (OECD, 2019). In this time, the teacher has responsibility over the classroom activities, guides, and accompanies these as well as the related learning processes (Ahtee et al., 2016). Research on psychosocial classroom learning environments has a strong tradition due to the early discovery of a relationship between positive classroom climate and academic performance and motivation, engagement, participation, and attitude towards school and teaching (e.g., Trickett \& Moos, 1973). Moreover, classroom climate influences students' growth and their academic, social, and emotional development (Evans et al., 2009). The classroom climate in a broader sense may also include physical environments (e.g., school building, classroom furniture) that likewise affect the learning and teaching of mathematics (Fahlström \& Sumpter, 2018). Yet, only recently has attention turned to the rich concept of classroom climate, and more research is needed in this context (Evans et al., 2009). Likewise, new methodological approaches are emerging with respect to studying activities in mathematics teaching, evaluating teaching quality, teacher-child relationship quality, and school and administrative adjustment (Ahtee et al., 2016; Harrison et al., 2007; Kearney \& Hyle, 2004; Lodge, 2007; Pehkonen et al., 2016).

Questionnaires have mainly been employed to research the complex construct of classroom social climate, with the focus most often on middle and secondary school (e.g., Bülter \& Meyer, 2015; Eder, 2002). Little research has been done at the elementary level, which included Grade 4 and higher (Bülter \& Meyer, 2015). Younger children, in particular, may have difficulties with reading and understanding survey items and expressing themselves clearly in writing or within interview contexts where they have to talk to an often relatively unfamiliar researcher, or providing verbally rich answers to questions they do not consider relevant (Pehkonen et al., 2016). Furthermore, both methods are particularly time-consuming and accompanied by partially unreliable student answers (Ahtee et al., 2016). Thus, these methods have shown not to be always reliable due to the participants' young age (e.g., Einarsdóttir, 2007; Pehkonen et al., 2016).

In recent decades, however, childhood research has experienced a paradigm shift that has had a comprehensive impact on qualitative research design and methods. 
While it was common to view children as objects by using methodologies such as direct observations, interviews, questionnaires, and test procedures, the shift has led to children being increasingly viewed as subjects in the research process (Hill, 1997). Among other things, this shift has led to the increased use of participatory and visual methods and processes in childhood research, such as photography, video, or drawing (Literat, 2013; Veale, 2005). Thus, there is an increased focus on methods in qualitative research that are primarily designed to engage and emphasize children's experiences, perspectives, and understandings, making them active agents in the research process (Einarsdóttir, 2007; Hill, 1997; Veale, 2005). The use of visual methods in the research process is not new in itself, however, children's participation is becoming increasingly important, and with it the research inquiry is becoming more participatory.

The work presented in this paper aimed at evaluating if and to what extent participant-produced drawings can be used to conceptualize and research the complex and multi-faceted construct of classroom social climate from the standpoint of primary grade students ${ }^{1}$ (Grades $3-6$ ). First, this paper provides theoretical and empirical foundations on drawings as a visual and participatory qualitative inquiry method in general and in mathematics education and on classroom social climate. After presenting the research process, a new classroom social climate model emerging from the students' drawings of their mathematics classroom is presented and exemplified on three drawings. Lastly, the power of participant-produced drawings concerning the conceptualization of the classroom social climate construct is discussed from a methodological, theoretical, and practical perspective.

\section{Participatory and visual methods in the research process with children: Drawing and drawings}

Drawing is a creative method based on inventive and imaginative processes with drawings as a research tool having the function of capturing children's individual experiences (Veale, 2005). Drawings as a visual method have been recognized as an alternative form of expression for (young) children. For children, drawing is much more than a simple representation of what they see before them; rather it can be

\footnotetext{
${ }^{1}$ In the federal states of Berlin and Brandenburg (Germany) primary education covers Grades 1 to 6 .
} 
understood as one way in which they are making sense of their experiences (Anning \& Ring, 2004). According to Lucquet (1913, 1923, in Anning \& Ring, 2004), the act of drawing can be generally regarded as a skill that can be acquired by all children up to a certain level. Lodge (2007), for instance, showed that even very young children (6 to 7-year-olds) developed a wide range of ways to represent learning in the classroom, such as drawing the common perceptions of learning in classrooms (e.g., dependence on the teacher, individual and separate learning activities), and social relationships with their teacher. Thus, already with young children this method provides a lens for research designs on classroom climate (Anning \& Ring, 2004; Malchiodi, 1998).

In contrast to classical data collection methods, the use of students' drawings showed significant benefits in qualitative inquiry, such as familiarity with the act of drawing, non-verbal expression (i.e., language mediation, language barrier), which is particularly beneficial when working with young students (Ahtee et al., 2016), and through simple alternation by quickly adding or deleting elements in the drawing (Einarsdóttir, 2007). Additionally, they can help students better recall and express more details about the events they depicted (Einarsdóttir, 2007). For instance, Barlow et al. (2011) stressed that the drawing process gives the child suggestions to talk about particularly relevant occurrences and events that are related to the situation depicted in the drawing. Furthermore, thought and speech bubbles can be used as an additional visual representation to facilitate children's description of their thoughts (Wellman et al., 1996). As such, verbal and drawn aspects together provide a deeper insight into the classroom climate (e.g., feelings, attitudes, values, norms, activities, communication) (Ahtee et al., 2016). Lastly, Kearney and Hyle (2004) found that using participant-produced drawings was more likely to accurately represent participants' experiences and emotions. Here, the participatory approach is characterized by establishing a rapport between the researcher and the participant as well as by a shift in the power (im)balance in the researcher-participant relationship, with a less researcher-imposed structure (Kearney \& Hyle, 2004). In other words, drawings function as a catalyst, helping participants to articulate their feelings, emotions, and lived experiences. Most importantly, they avoid adults interpreting children's drawings other than intended by the child (Einarsdóttir, 2007). Consequently, the participant approach allows for depth of discussion, the participant's shaping of agenda, and encourages collaborative meaning-making as well as reliable and trustworthy data (Kearney \& Hyle, 2004). 


\section{Conceptualizing classroom social climate}

\subsection{Classroom social climate construct and relevance}

The classroom is an environment in which students develop both interpersonal and academic skills (Trickett \& Moos, 1973). Furthermore, it is a social context for learning, which with time develops a distinct social climate or feel having certain demand characteristics (e.g., Evans et al., 2009; Moos \& Moos, 1978; Trickett \& Moos, 1973). To date, there is no uniform definition of the construct classroom climate, but it is described through its fundamental supporting elements (Eder, 2002). In a general sense, Eder (2002) emphasized that classroom climate defined the quality of social relationships within a classroom. Within different disciplines various approaches to the conceptualization and assessment of environments have been used. One often-applied approach is based on the concept of the so-called perceived environment (e.g., Eder, 2002; Moos \& Moos, 1978; Trickett \& Moos, 1973). This approach is based on the contention that the environment of a particular setting is defined by the shared perceptions of its members along with several environmental domains over a longer period (Moos \& Moos, 1978). According to Trickett and Moos (1973), nine dimensions of classroom climate can be used in conceptualizing the individual dimensions characterizing diverse psychosocial environments. These fall under three general conceptual domains or categories: (1) Relationship, the degree to which individuals in the environment help and support each other, and to which they are involved in the class and its activities (i.e., involvement, affiliation, teacher support); (2) Personal Development, the degree to which self-enhancement can occur (i.e., task orientation, competition); and (3) System Maintenance and System Change, the degree to which the environment is orderly, clear in expectations, maintains control, and can change (i.e., order and organization, rule clarity, teacher control, innovation). On the other hand, Evans et al. (2009) conceptualized classroom climate as a function of three different components: academic, referring to the pedagogical and curricular elements of the learning environment; management, referring to discipline styles for maintaining order; and emotional, referring to the affective interactions within the classroom.

The pedagogical goal of schooling is to enable and support the development of students' cognitive, social, and practical skills which generally includes imparting knowledge, but also fostering the social climate among students (Radatz \& Rickmeyer, 1991). In this regard, the classroom is a significant social environment in children's 
development (e.g., Evans et al., 2009; Moos \& Moos, 1978; Trickett \& Moos, 1973). In particular, communication between the teacher and her/his pupils is central to pupils' formalization of mathematical concepts and procedures (Ahtee et al., 2016). Furthermore, Meyer (2019) outlined ten criteria of good teaching, which also included a climate conducive to learning. Thus, in that manner, the classroom climate has broad effects, ranging "from an increase in the joy of learning or the reduction of school disenchantment and (performance) anxiety, the improvement of classroom discipline, the increase in the willingness to exert effort and cooperation, to the improvement of cohesion and self-esteem" (Bülter \& Meyer, 2015, p. 25). A growing literature points to the importance of classroom social climate as one of the determinants of students' academic performance and motivation, engagement, participation, and attitude towards school and teaching. However, little attention is given to classroom social climate in the context of the mathematics learning milieu, and if so, studies only provide insights into specific aspects of the classroom social climate during mathematics lessons, such as activities of classroom protagonists (Ahtee et al., 2016) or their communication (Pehkonen et al., 2016).

\subsection{Measuring classroom social climate}

Depending on the grade level, different quantitative instruments were developed to measure the classroom social climate, such as Moos' Classroom Environment Scale (CES), which laid a foundation in school and classroom climate research at the secondary level (Evans et al., 2009). Concretely, the CES included 90 items evenly distributed across nine dimensions which consisted of (a) Involvement, (b) Affiliation, (c) Teacher support, (d) Task orientation, (e) Competition, (f) Order and organization, (g) Rule clarity, (h) Teacher control, and (i) Innovation (Fisher \& Fraser, 1983a; Fraser, 2012; Trickett \& Moos, 1973; Trickett \& Quinlan, 1979). The dimensions are explained as follows: (a) Involvement examines the extent to which students show attentive interest, participate in discussions, complete extra work, or enjoy being in class; (b) The extent to which students help others, try to get to know others better, and enjoy working together are all part of the affiliation dimension; (c) Teacher support reflects the extent to which the teacher helps, trusts, and shows interest in students; (d) Task orientation examines the extent to which the classroom activities are centered around the achievement of specified academic objectives; (e) Competition examines the students' competitive behavior among each other in terms of grades and recognition; (f) Order and organization examines how students 
interact with each other (i.e., behaving in an orderly, polite, and quiet manner) and how overall classroom activities are organized; (g) Clarity of rules considers the degree to which the rules of conduct are clearly understood, and the degree to which the teacher consistently deals with rule violations; (h) Teacher control examines the amount and the extent of rules governing students' behavior in the classroom; (i) In terms of innovation, the extent to which the teacher plans new, unusual, and varying activities and techniques as well as students' contribution to classroom planning and creative thinking is examined (Fraser, 2012; Trickett \& Moos, 1973). These nine dimensions fall into the three main categories, namely Relationship (a-c), Personal Development (d-e), and System Maintenance and System Change (f-i) (Fisher \& Fraser, 1983a; Trickett \& Quinlan, 1979). Thus, by using the CES, it was possible to capture the essence of the psychosocial classroom environment, to obtain systematic data on classroom social climate (e.g., teachers' behavior, teacher-student interactions, interactions among students), and to determine and understand the effects of socialization in a wide variety of classrooms as perceived by different individuals in the same setting (Fisher \& Fraser, 1983a).

Only one instrument, namely the My Class Inventory (MCI) was developed on the basis of the CES to measure the perception of an actual environment by elementary grade students (8 to 12 years of age) (Fraser \& Fischer, 1983). It contained only five scales, namely, Satisfaction, Friction, Cohesiveness, Competitiveness, and Difficulty. In terms of placement in Moos' (1974) schema, the first three affiliate with the relationship category, and the latter two with the personal development category (Fraser, 2012). Furthermore, the wording of items was simplified to enhance readability, and instead of a 4-point Likert scale, a 2-point scale was used. However, only a handful of studies used the MCI starting at the earliest in Grade 4, but still mainly in middle school classes.

There are many other instruments in addition to the ones mentioned (see Bülter \& Meyer, 2015; Fraser \& Fischer, 1983), the comparison of which showed that the basic concept of classroom climate is broad but generally homogeneous. On the one hand, it comprised relationship characteristics (i.e., teacher-student, studentstudent), and, on the other hand, teaching characteristics (e.g., choice of teaching methods, internal differentiation, design of the learning environment) (Bülter \& Meyer, 2015). Thus, the classroom climate is a multi-faceted construct "made up of a large number of components, which can be reduced to factors in a variety of ways" (Evans et al., 2009, p. 141) depending on the type of environment (Fraser, 2012). 
Although a broad focus on the concept of classroom social climate makes perfect sense, in an extreme form, it would amount to having to include all aspects of good teaching (Bülter \& Meyer, 2015). From a research perspective, it is more of an advantage to start from a narrow concept of classroom social climate since its different facets are by no means uniform.

In recent years, it has been shown that the use of creative methods, such as drawings, provide a multi-dimensional and holistic view of young students' latent experiences, ideas, and perceptions in the classroom concerning communicative and social aspects of mathematics teaching (e.g., Ahtee et al., 2016; Glasnović Gracin \& Kuzle, 2018; Pehkonen et al., 2016). For instance, Ahtee et al. (2016) focused on developing a method to determine teachers' and pupils' activities during a mathematics lesson. As a result of the analysis of students' drawings two inventories emerged. The first inventory contained 14 separate items organized into six groups that included diverse teacher activities (e.g., giving information on mathematics, giving feedback, asking questions), whereas the second one focused on students' activities that were organized into five groups that included altogether 22 items (e.g., activities of a single student, student-student discussion on mathematics, studentteacher discussion on mathematics). In that manner, from a research and practical perspective both inventories opened a window into students' perceptions of their teacher's and their classmates' activities in mathematics lessons, and how different aspects change over time (Ahtee et al., 2016). Glasnović Gracin and Kuzle (2018), on the other hand, conducted an exploratory case study with four elementary school children with the goal of capturing the social dimension of the classroom climate in geometry lessons. In their analysis, they combined the inventories of Pehkonen et al. (2016) and Ahtee et al. (2016) by focusing on the teacher's communication (i.e., poses questions, gives a task, gives instructions, teaches, gives feedback, maintains order, quietly observes students working) and students' communication (i.e., answers the teacher's question, makes/asks/thinks a remark/question in connection to teaching, solves a task, asks for help, discusses something with other student(s), makes/thinks an improper remark, keeps order, works quietly without communicating with other students). Though Glasnović Gracin and Kuzle (2018) reported on the benefits of using drawings to capture students' perception of the classroom social climate, the two scales were imposed on the data analysis. Furthermore, the sample was too small to capture other aspects of the classroom social climate, and in that manner, it was not possible to develop a comprehensive analytical tool. Thus, the general utility of 
the inventory as a research tool appeared to be insufficient in its current form in terms of gaining a thorough insight into the classroom social climate using participantproduced drawings.

\subsection{Purpose of the study}

To date, it has not been possible to make an area-wide statement about the classroom social climate in primary grade mathematics (Eder, 2002). One reason for this is the lack of a suitable instrument since the previous studies mainly employed quantitative methods (e.g., Bülter \& Meyer, 2015). In order to obtain meaningful information concerning the classroom climate from visual research methods, such as drawings, viable models and tools need to be developed that focus exclusively on the social aspects (e.g., actions of the teacher and the students, classroom activities, norms in the classroom). Studies in this area using students' drawings (e.g., Ahtee et al., 2016; Glasnović Gracin \& Kuzle, 2018; Pehkonen et al., 2016) could not provide a comprehensive picture of what was happening in the classroom. Although Moos' CES instrument (1973, after Trickett \& Moos, 1973) provides an important basis for creating such a model and tools, it requires adaptation with respect to the used method (i.e., students' drawings), breadth of scales (i.e., other aspects of classroom social climate), and the participants' age (i.e., elementary grade students).

This being said, the paper's overarching goal is to answer the question of how and to what extent the model can capture the many aspects of classroom climate in different mathematics lessons using participant-produced drawings. Concretely, the purpose of the study was - by using an explorative qualitative research design - to (1) develop analytical tools that can be used in a qualitative inquiry on classroom social climate when using participant-produced drawings in the context of school mathematics (arithmetic and geometry ${ }^{2}$ lessons), (2) evaluate the extent to which the participant-produced drawings can be used when researching the complex and multifaceted construct of classroom social climate using participant-produced drawings from the standpoint of primary grade students (Grades $3^{-6}$ ), and (3) present a modification and further development of existing classroom climate models from the standpoint of primary grade students by using participant-produced drawings. The following research questions guided the study:

\footnotetext{
${ }^{2}$ Geometry lessons refer to two standards: space and form, and measurement.
} 
1. What different aspects of classroom social climate emerge through participantproduced drawings?

2. To what extent do different classroom social climate characteristics differ depending on the context of mathematics lessons?

\section{Research context}

\subsection{Research design and subjects}

For this study, an explorative cross-sectional qualitative research design using participant-produced drawings was chosen. The study participants were 227 elementary school students (Grades 3-6) from two federal states in Germany. This age group was optimal as they have already gathered enough experience in school mathematics, and their drawing skills are already solid to high enough. Typical case sampling as a type of purposive sampling was utilized as a way of collecting rich and in-depth data (Patton, 2002).

\subsection{Data collection instruments and procedures}

The research data were collected in a one-to-one setting between a student and the first author of the paper which consisted of (a) audio data, (b) document review, and (c) a semi-structured interview. The audio data (a) were composed of the students' unprompted verbal reports during the drawing process, and prompted verbal reports after the drawing process. For the document review (b), each student was given a piece of paper with the following assignment: "Dear , I am Anna and new to your class. I would like to get to know your class better. Draw two pictures of your mathematics lessons. The first drawing should show what your arithmetic lessons are like and how you view them. The second drawing should show what your geometry lessons are like and how you view them. Include in each drawing your teaching group, the teacher, and the students. Use speech bubbles and thought bubbles to describe conversation and thoughts. Mark the student that represents you in the drawing by writing "ME". Thank you and see you soon! Yours Anna." The drawings were then used as a catalyst for a semi-structured interview (c) as suggested by Kearney and Hyle (2004). During the interview both a free description of the drawing on the part of the child were given (e.g., "Describe your picture to me.”), and specific questions based on the child's description were posed (e.g., "You said/drew that your teacher stands 
at the blackboard/sits at the table a lot. How does this change in the course of the lesson?", "I see you only drew one child, where are the other children?", "How does the position of you students change during the lesson?”, Can you tell me what you did in the lesson?", "What do the other students say when someone is not paying attention?”). Multiple data sources were used to assess the consistency of the results, and to increase the validity of the results as was suggested by Einarsdóttir (2007) when employing visual research methods.

\subsection{Data analysis}

The drawings were analyzed after all the data had been collected. As suggested by Patton (2002), multiple stages of the analysis using an analytic approach were performed with a focus on developing two inventories (arithmetic, geometry) to determine different facets of classroom social climate in the students' data. This process contained the following steps: transcribing audio data, analysis of drawings with respect to Moos' conceptualization of classroom social climate (i.e., relationship, personal development, system maintenance and system change), confirmation of the interpretation and coding of other facets included in the students' data, and developing dimensions, subdimensions, and scales for each general category of classroom social climate by clustering similar concepts. The first author transcribed the audio data and analyzed the drawings separately with another researcher using Moos' conceptualization of classroom social climate. Specifically, we started with a deductively created coding manual that provided descriptions of each general category of the CES (Fisher \& Fraser, 1983b; Trickett \& Moos, 1973). This allowed us to assign a particular general category to items that emerged in the students' data. However, given the design (i.e., participant-produced drawings, study sample) and implementation context (i.e., mathematics lessons), we needed to revise Moos' model by structuring and expanding it with the goal of developing multi-faceted inventories. Here, each general category, as well as descriptions of each general category, were reexamined, refined, or expanded based on the students' data taking into account different expression forms. From this theoretical basis, the three categories of the coding manual, (1) personal relationship, (2) personal growth, and (3) order, evolved. Thus, the general categories were adapted to data emerging through participantproduced drawings. Afterward, the same researchers focused on separately developing two inventories with dimensions, subdimensions, and scales for each general category of classroom social climate by going through all the drawings starting 
with Grade 3 and ending with Grade 6 using both deductive (e.g., CES, MCI) and inductive approaches. For this purpose, the drawings were viewed one by one and the passages in the interviews that referred to the social aspects or the passages that defined situations or objects in the drawing more clearly were marked. The inventories were discussed to obtain full agreement. Concretely, the nature of each dimension, subdimension, and scale was discussed, which allowed the refining of each descriptor, and new dimensions, subdimensions, and/or scales emerged from the students' data. If a descriptor was not given, the researchers discussed the nature of the descriptor before developing a new dimension, subdimension, or scale, and extending the analytical tools. All procedures and decisions were recorded in an audit trail, which also ensured trustworthiness and rigor (Patton, 2002). Lastly, both authors validated the developed inventories through an iterative process of coding the drawings once again, and constant comparison in order to obtain full agreement as suggested by Creswell and Miller (2000). Here, analyst triangulation contributed to the verification and validation of qualitative analysis (Creswell \& Miller, 2000; Patton, 2002). Consequently, this allowed the development of very detailed and refined inventories to analyze students' perceptions of the classroom social climate in mathematics lessons.

\section{Rethinking the construct of classroom social climate using participant-produced drawings}

\subsection{Classroom social climate as seen in the students' drawings of mathematics lessons: an emerging model}

On the basis of the analysis of the students' data from both arithmetic and geometry lessons, we conceptualize classroom social climate as a function of three conceptual categories, namely Interpersonal Relationship, Personal Growth, and Order. Each of these is described through its dimensions, subdimensions and scales.

The first category (see Table 1) Interpersonal Relationship refers to nature, the intensity of personal relationships, and the mutual influences of the teacher and the students within the classroom, including social, pedagogical, and mathematical aspects. Verbal and non-verbal communication of the teacher, Verbal and non-verbal communication of the students, and Organization are conceptualized as interpersonal relationship dimensions. The first dimension is specified through the teacher's position in the classroom and teacher's support. The second dimension is specified 
through the students' position in the classroom, participation, and affiliation. The third dimension is specified through the working method and classroom seating arrangement.

Table 1. Description of the "Interpersonal Relationship" category

\begin{tabular}{|c|c|c|}
\hline \multicolumn{3}{|c|}{ 1. Category: Interpersonal Relationship } \\
\hline Dimension & Subdimension & Scale \\
\hline \multirow{2}{*}{$\begin{array}{l}\text { Verbal and non- } \\
\text { verbal } \\
\text { communication of } \\
\text { the teacher }\end{array}$} & Position in the classroom & $\begin{array}{l}\text { In front of the blackboard, Among students, At the } \\
\text { desk, Somewhere in the classroom }\end{array}$ \\
\hline & Support by the teacher & $\begin{array}{l}\text { Assistance, Positive feedback, Negative feedback, } \\
\text { Mathematics-related question, Mathematics- } \\
\text { related statement, Observation, Non-mathematical } \\
\text { comment, Passive }\end{array}$ \\
\hline \multirow{3}{*}{$\begin{array}{l}\text { Verbal and non- } \\
\text { verbal } \\
\text { communication of } \\
\text { the students }\end{array}$} & Position in the classroom & $\begin{array}{l}\text { At the blackboard, At the table, Next to the } \\
\text { teacher, In front of the blackboard, Amongst other } \\
\text { students, Somewhere in the classroom }\end{array}$ \\
\hline & Participation & $\begin{array}{l}\text { Working on assignments at the table, Working on } \\
\text { assignments on the blackboard, Listening, } \\
\text { Responding, Questioning, Asking for assistance, } \\
\text { Review, Discussion, Positive expression, Negative } \\
\text { expression, Non-mathematical comment, Passive }\end{array}$ \\
\hline & Affiliation & $\begin{array}{l}\text { No communication with other students, Student- } \\
\text { student communication, Student-student } \\
\text { encouragement, Student-student help request, } \\
\text { Student-student support, Negative comments } \\
\text { towards other students }\end{array}$ \\
\hline \multirow[t]{2}{*}{ Organization } & Working method & $\begin{array}{l}\text { Teacher-centered instruction (frontal), Individual } \\
\text { work, Group work, Working with a partner, } \\
\text { Work/discussion while sitting in a (half-)circle }\end{array}$ \\
\hline & $\begin{array}{l}\text { Classroom seating } \\
\text { arrangement }\end{array}$ & $\begin{array}{l}\text { Traditional classroom arrangement, U-shaped } \\
\text { arrangement, Mixed arrangement, (Half-)circle } \\
\text { arrangements, Group tables }\end{array}$ \\
\hline
\end{tabular}

The second category Personal Growth refers to the goal orientation and clarity of the lesson objective. A lesson goal can be represented by mathematical content or an assignment on the backboard, the teacher identifying the goal of the lesson or students working on their assignment. Alternatively, the lesson objective can be pursued by using different teaching materials specific to geometry (e.g., geometric forms, models, tools) and arithmetic (e.g., inch-worms, number line, place value board), which can be utilized by classroom protagonists (teacher, students) (see Table 2). 
Table 2. Description of the "Personal Growth" category

\begin{tabular}{ll}
\hline & 2. Category: Personal Growth \\
\hline Dimension & Scale \\
\hline Goal orientation & $\begin{array}{l}\text { Goal of the lesson, Presence of mathematical content, Teacher's } \\
\text { identification of the mathematical content, Students working on } \\
\text { the assignment }\end{array}$ \\
\hline Teaching materials and tools & $\begin{array}{l}\text { Geometry: 2D-shapes and models, 3D-solids and models, } \\
\text { geometric tools (e.g., ruler, protractor, compass), poster } \\
\\
\text { Arithmetic: number line, place value board, poster }\end{array}$ \\
\hline
\end{tabular}

The third category Order refers to the social norms and maintenance of order in the classroom. We understand social norms as shared principles of behavior that are considered acceptable in a group. Here, not only the teacher, but also the students are responsible for proper conduct, keeping order, and behaving properly. Whether behavioral prompts need to be made by the teacher or the students suggests the extent to which rules are established, order and behavior prevail in the classroom, and the teacher is in control of the class (see Table 3 ).

Table 3. Description of the "Order" category

\begin{tabular}{lc}
\hline & 3. Category \\
\hline Dimension & Scale \\
\hline Keeping order & Student led, teacher led \\
\hline
\end{tabular}

The following three figures (Figures 1, 2, and 3) illustrate the coding of the students' drawings. Figures 1 and 3 illustrate geometry lessons, and Figure 2 illustrates an arithmetic lesson. In that manner both the similarities and differences between the two analytical tools can be discerned. The drawings do not represent a prototypical drawing, but rather have been selected on the basis of data richness and versatility. For example, all three drawings contain speech or thought bubbles whereas some of the drawings were very simple, having only a schematic picture of the classroom with the students substituted by their desks or represented by stick figures. In the description of the drawings, we used the coding system presented in Appendices $\mathrm{A}$ and $\mathrm{B}$ (e.g., $\mathrm{D}=$ domain, letters $\mathrm{A}$ to $\mathrm{C}=$ dimensions, ordinal numbers = subscales, $\mathrm{T}=$ teacher, $\mathrm{S}=$ student). The number in brackets gives the number of drawn persons who fall into this category. For example, code D1A.1.T means the following: D (abbreviation for the word 'domain'), $1 \mathrm{~A}$ (Which dimension is considered?), 1 (ranking of the dimension in the domain, here: first domain and dimension with subdimension 'position in the room'), $\mathrm{T}$ (Is teacher $\mathrm{T}$ or student $\mathrm{S}$ 
considered?). That is, we consider dimension $1 \mathrm{~A}$ 'verbal and nonverbal communication of the teacher'. It is the first scale 'in front of the blackboard' in the subdimension 'position in the room' (see Appendices A and B). Here the teacher is considered. For us, this means in summary that the teacher is located in the classroom in front of the blackboard. It is recommended to refer to the coding manuals while reading the following explanations (see Appendices A or B).
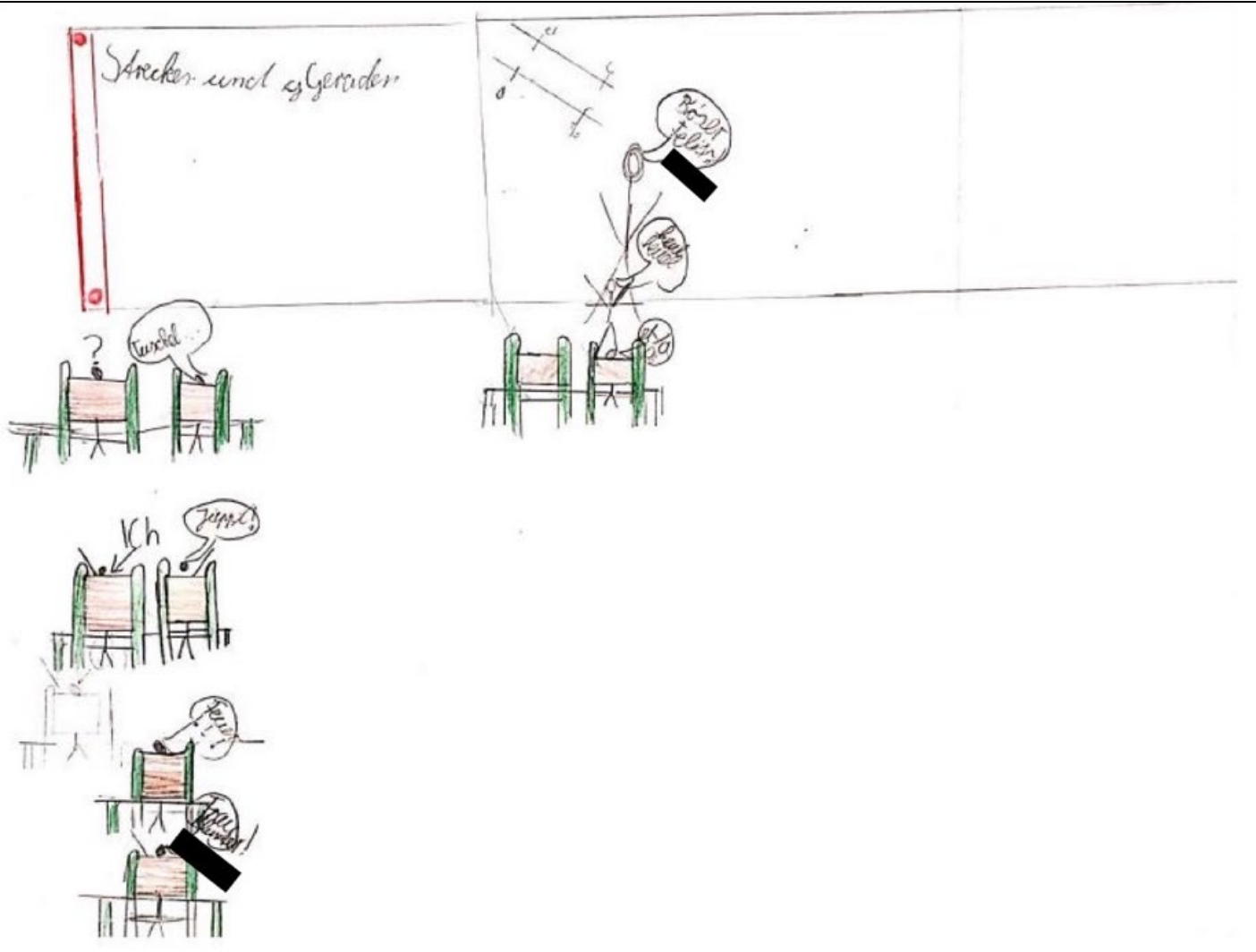

The teacher is standing in front of the blackboard. She is making a non-mathematical comment ("Bad Felix!"). In total eight students are illustrated in the drawing. Seven of them are sitting at their desks. One child is standing in front of the blackboard. Three students are raising their hands to participate in a discussion. Six students express non-mathematical content (e.g., "Fire!!!", "Ha”, "Yippie!”). One student is making a negative comment to another student by saying "cry, cry".

In the classroom the teacher is standing in front of the class, and teaching a lesson on line segments and rays which are illustrated on the blackboard. The heading on the blackboard also makes the goal and the content of the lesson clear. The tables are arranged in rows.

The teacher is keeping order by admonishing a student by saying "Bad Felix!"

Coding of 1st domain "Interpersonal Relationship": D1A.1.T: Position in the classroom; in front of the blackboard. D1A.13.T: Support by the teacher; non-mathematical comment. D1B.2.S(7): Position in classroom; at the table. D1B.4.S(1): Position in classroom; in front of the blackboard. D1B.16.S(3): Participation; discussion. D1B.19.S(6): Participation; non-mathematical comment. D1B.28.S: Affiliation; negative comments towards other students. D1C.1: Working method; teacher-centered instruction. D1C.7: Classroom seating arrangement; traditional classroom arrangement.

Coding of 2nd domain "Personal Growth": D2A.1: Goal orientation; the goal of the lesson is clear. D2B.1: Teaching materials and tools; 1D-objects.

Coding of 3rd domain "Order": D3A.2: Keeping order; led by the teacher.

Figure 1. A Grade 3 student's drawing of a geometry classroom with codes. 


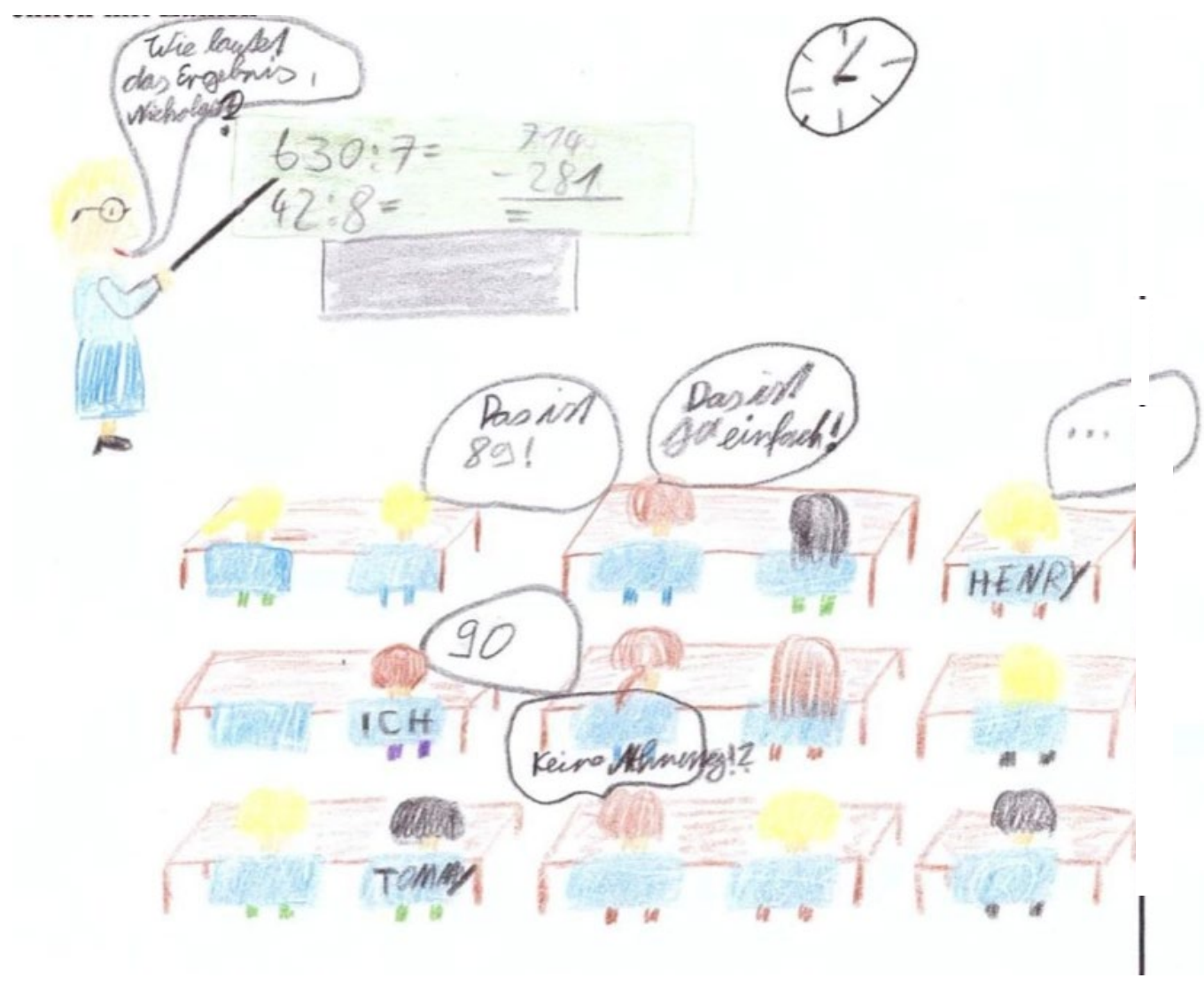

In the classroom the teacher is standing in front of the class and teaching. The tables are arranged in rows.

Three mathematical problems (e.g., a subtraction task, two divisional tasks) are illustrated on the blackboard. The goal of the lesson is clear. The teacher is making the mathematical content clear by asking a question about it. The students work on the assignments orally. The subtraction task is to be solved in writing.

There are no behavioral demands on the part of the students or the teacher in the drawing or the interview.

Coding of 1st domain "Interpersonal Relationship": D1A.1.T: Position in the classroom; in front of the blackboard. D1A.10.T: Support by the teacher; mathematics related question. D1B.2.S(14): Position in the classroom; at the table. D1B.9.S: Participation; working on the assignment at the table. D1B.12.S(1): Participation; responding. D1B.17.S(1): Participation; positive expression. D1B.18.S(1): Participation; negative expression. D1B.23.S: Affiliation; no communication with other students while working on the assignments. D1C.1: Working method; teacher-centered instruction. D1C.7: Classroom seating arrangement; traditional classroom arrangement.

Coding of 2nd domain "Personal Growth": D2A.1: Goal orientation; the goal of the lesson is clear. D2A.3: Goal orientation; the teacher shows the mathematical content. D2A.4: Goal orientation; students work on their assignment. D2B.2: Teaching content/materials and tools; subtraction task. D2B.4: Teaching content/materials and tools; division task. D2B.7: Teaching content/materials and tools; calculating strategies.

Coding of 3rd domain "Order": D3A.3: Keeping order; unavailable.

Figure 2. A Grade 4 student's drawing of an arithmetic classroom with codes. 


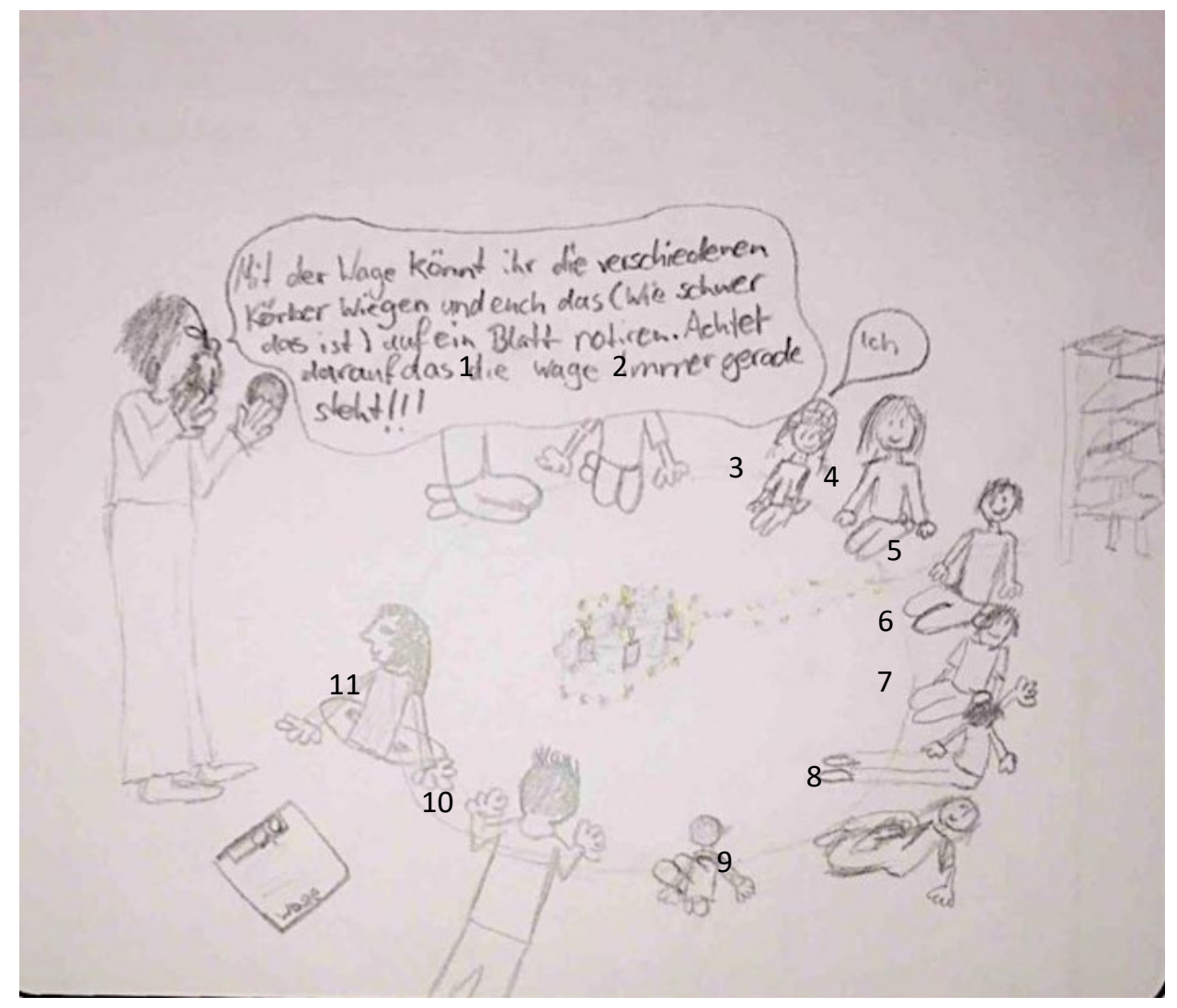

The teacher is standing amongst students who are sitting in a circle. The teacher is explaining the task and at the same time providing help by giving hints for better handling of the task: "Make sure that the (balance) scale is always straight!" The teacher is making a mathematically related statement: "With the (balance) scale you can weigh different objects (how heavy they are) and write it down on a sheet of paper." The students are sitting on the classroom floor in a circle. Students 3-5 and 8-11 are listening to the teacher. The pairs of students 1 and 2 and 6 and 7 are talking to each other about non-mathematical topics while the teacher is explaining the task. Students 6 and 7 have their faces directed towards each other. Students 1 and 2 have no faces to be seen but their legs are directed towards each other, whereupon one can assume that they are talking to each other since student 1 's legs are pointing towards student 2 . The content of their discussion is not known.

The teacher is explaining the work assignment. The goal of the lesson is clear. She is identifying the mathematical content (i.e., weighing objects by using a balance scale) by giving explanations. The teacher is holding two objects in her hands. In the circle there are different objects that the children are supposed to weigh.

There are no behavioral demands on the part of the students or the teacher in the drawing or the interview.

Coding of 1st domain "Interpersonal Relationship": D1A.2.T: Position in the classroom; amongst students. D1A.7.T: Support by the teacher; assistance. D1A.11.T: Support by the teacher; mathematics related statement. D1B.6.S(11): Position in the classroom; somewhere in the classroom. D1B.11.S(7): Participation; listening. D1B.19.S(4): Participation; non-mathematical comment. D1B.24.S(4): Affiliation; student-student communication. D1C.5: Working method; work/discussion while sitting in a circle. D1C.10: Classroom seating arrangement; circle arrangement

Coding of 2nd domain "Personal Growth" D2.1: Goal orientation; the goal of the lesson is clear. D2.3: Goal orientation; the teacher identifies the mathematical content. D2.8: Teaching materials and tools; 3D-models.

Coding of 3rd domain "Order": D3A.3: Keeping order; unavailable.

Figure 3. A Grade 5 student's drawing of a geometry classroom with codes.

The results presented in Figures 1-3 exemplify again the structure of the model. Furthermore, the fine-grain features of the model are obvious with different subdimensions and scales emerging from the students' data. The subdimensions divide the dimensions in the coding manual into much more concrete aspects (i.e., 
scales). For instance, using only a subdimension without scales, it would have only been possible to record whether the teacher is in the room or not. However, through the scales assigned to the subcategories "position in the room" both regarding the teacher and the students, the exact position could be identified. Thus, it can be determined whether the teacher is, for example, at the blackboard, at the teacher's desk, among students or somewhere else in the room. In that manner, the developed inventories allow the obtaining of rich information about the classroom social climate from the students' perspective in the mathematics classrooms.

\subsection{A comparison of the analytical tools: geometry and arithmetic lessons}

In terms of commonalities, the analytical tools for geometry and arithmetic lessons show an identical structure in the form of a table in which the domains, dimensions, subdimensions, and scales are presented. Furthermore, they do not differ with regard to the three main domains and the associated dimensions with subdimensions. Differences exist only in the scales themselves or their description (i.e., specific aspects assigned to the dimensions and/or subdimensions).

In particular, a significant difference lies in the scales of dimension $2 b$, namely Teaching materials and tools, which is assigned to the second domain Personal Growth. While the subcategories in the coding manual for geometry instruction refer primarily to plane figures and shapes, geometric solids, angles, distances, and lines, and working with geometric tools and $2 \mathrm{D}$ as well as $3 \mathrm{D}$ models, the coding manual for arithmetic instruction focuses in particular on basic arithmetic operations. Here, in addition to addition, subtraction, multiplication and division tasks, arithmetic procedures or calculating with variables and fractions can also be coded. In addition, the analysis tool for arithmetic instruction refers to aids such as the number line or the place value table. The reason for this is that the teaching materials and tools in geometry instruction differ from those in arithmetic instruction. While the scales in the analytical tool for geometry instruction refer primarily to geometry specific materials and tools (e.g., 2D- and 3D-models), the scales in the analytical tool for arithmetic instruction focus on arithmetic specific materials and tools (e.g., number line, place value table). However, both analytical tools include the scales Other content and Other tools. For instance, in geometry instruction content such as angles, distances, 1-D objects (e.g., lines, line segments) were illustrated, whereas in arithmetic instruction content such as addition, subtraction, multiplication and 
division tasks, arithmetic procedures or calculating with variables and fractions. Thus, the scale was developed in order to be able to capture contents and tools that are drawn less frequently or to capture all content, and materials that do not have a specific subcategory which would otherwise distort the results of the evaluation.

Furthermore, minor differences can be found in the explanations of the scales. For example, looking at the scale "Mathematics-related question" (D1A.10.T) within the subcategory Support by the teacher, in the explanation for geometry instruction, the following example can be found "What is the name of the solid?", whereas in the explanation for arithmetic lessons "What is the result of the addition task?". Similarly, the description of the scale Mathematics-related statement (D1A.11.T) differed between the two manuals. In both cases the teacher expressed a mathematical statement or gave students a particular assignment. However, the nature of the two differed; in each case they both reflected the content of the lesson type. For instance, in the case of geometry lessons, statements and/or assignments mostly dealt with geometrical shapes and solids (e.g., "This shape is called a parallelogram.", "Draw a diagonal please."). In the case of arithmetic lessons, statements and/or assignments dealt with different topics from "Numbers and Operations standard" (e.g., "Numbers $2,3,5, \ldots$ are examples of prime numbers.", "Please continue the fifth row of multiplication tables.”).

As noted, the coding manuals are similar in all listed domains, dimensions and subdimensions, except in the above mentioned two cases regarding the scales or their description. The reason for this is that, for example, although the teacher's position may differ between geometry and arithmetic instruction, it may be fundamentally the same. The same is true for the subdimensions Support by the teacher, Position in the classroom of the students, Participation, Affiliation, Working method, Classroom seating arrangement, and the dimensions Goal orientation and Keeping order. In all dimensions, significant differences could be discovered in the drawings. For instance, in Figure 2 the teacher asked the question "What is the answer to $630: 7$ ?" (D1A.10.T) with one student responding "9o." (D1B.12.S). In the geometry lessons, such questions and responses could not be found, but rather "What solid can you identify?" (D1A.10.T) with a student response "I can see a cube." (D1B.12.S). Nevertheless, there was always the possibility that the same subdimensions will be identified. This would have been less likely in the dimension Teaching materials and tools, which is why the associated scales are very different from each other in that the learning content and materials have been adapted to the field of mathematics. 
In our study, we used participant-produced drawings as a data source pursuing three goals, namely (1) conceptualize the complex and multifaceted construct of classroom social climate from the standpoint of primary grade students, (2) evaluate the utility of drawings when researching the construct of classroom social climate, and (3) provide two analytical tools for researching classroom social climate in the context of mathematics lessons.

As it was not obvious whether existing models of classroom social climate, especially Moos' (1999) model of classroom social climate, worked for the approach of using participant-produced drawings, in the first step we were concerned with clarifying whether and how this framework can be understood in this context. For that reason, the qualitative inquiry process was guided by three principles. First, consistency with literature describing the characteristics of the mathematics classroom. Secondly, individual insider characterization of the classroom through students' eyes by using participant-produced drawings. Thirdly, the ageappropriateness of the model without sacrificing its depth. Since the model turned out to be suitable, it was used as a basis for developing multi-faceted inventories which both refined and expanded Moos' (1999) model of classroom social climate on the basis of produced data. These have evolved from the basic principles of the CES (e.g., Fisher \& Fraser, 1983a, 1983b; Trickett \& Moos, 1973; Trickett \& Quinlan, 1979), but still reflecting its multifaceted nature made up of a large number of components. Specifically, each domain is divided into dimensions, dimensions into subdimensions with accompanying scales to capture different aspects from the students' data (i.e., drawings, semi-structured interview). Based on the qualitative analysis of participantproduced drawings, we proposed a possible further development of existing classroom climate models reported in the literature (e.g., Bülter \& Meyer, 2015; Eder, 2002; Evans et al., 2009; Fraser, 2012; Fraser \& Fisher, 1983; Trickett \& Moos, 1973) to better understand structure, functions, and processes in a mathematics classroom. The final version of the analytical tools for eliciting, describing, and analyzing the classroom social climate in elementary school mathematics lessons can be found in Appendices A and B.

The model and with it both inventories elicit many similarities, but also differences with existing classroom climate models, such as the CES. Regarding the first domain Interpersonal Relationship, in comparison to Moos' CES (Fisher \& Fraser, 1983a, 1983b) where the domain Relationship is described through three dimensions (i.e., 
involvement, affiliation, teacher support), our model is wider and more versatile with respect to its different aspects (see Table 1). On the other hand, the domain Personal Growth has a different character than Personal Development in the CES. In our model, the focus is more on the academic and pedagogical aspect of teaching, especially by adding the dimension Teaching materials and tools. Task orientation in the CES is rather narrow and was expanded in our model. No data relevant to the CES dimension Competition emerged from the students' data and this dimension is not part of our model. Lastly, compared to Moos, who described the domain System Maintenance and System Change with four dimensions (i.e., order and organization, rule clarity, teacher control, innovation) (Fisher \& Fraser, 1983b), the qualitatively obtained data revealed only one aspect, that is, who is in charge of keeping order, which can conceptually be understood as a combination of Moos' first three dimensions (see Table 3). Thus, the domain is named Order. Here the participantproduced drawings did not allow a more fine-grained analysis to distinguish between Moos' different dimensions.

The students' drawings did not only reveal social aspects of the classroom learning milieu but also the physical environment of both lessons. For instance, the students drew classroom furniture (e.g., tables, chairs, blackboard, whiteboard, shelves, storage racks). Thus, the students perceive not only the teacher, other students, and mathematical content (i.e., arithmetic, geometry) as a part of a teaching and/or learning situation, but also the physical environment itself (Fahlström \& Sumpter, 2018).

With respect to the two coding manuals emerging from that data, there were more commonalities (i.e., identical structure: domains, dimensions, subdimensions, scales as well as content of these) than differences. The two differed only in the scales themselves or their description. Because of the many similarities between the coding manuals, it would then be interesting to see how arithmetic instruction and geometry instruction differ from each other from the students' perspective. How are the desks arranged in the geometry classroom? How are the desks arranged in the arithmetic classroom? What are the working methods of the students in the geometry classroom? What are the working methods in the arithmetic classroom? Or, do the students help each other in the geometry class? Do they help each other in the arithmetic lessons? Due to the similarities of the instruments, it would be possible to draw a direct comparison between the students' perception on arithmetic and geometry lessons from a social perspective. 


\section{Concluding comments and recommendations}

The findings created by the use of participant-produced drawings in this study, together with those reported in the literature, led to a number of observations about the application of this methodology. These findings provide areas of consideration for other researchers who are considering using visual research methods in their work with (young) students on classroom (social) climate in mathematics education or in educational settings in general. These recommendations and associated explanations are given in the following lines.

Participant-produced drawings create a window into students' perceptions of mathematics classroom learning milieu from a social perspective, making them viable tools for researchers who seek access to this research area. In mathematics education research, drawings and the processes by which they are made open a new way of gaining insight into the classroom social climate in mathematics lessons without imposing the researchers' perspective (e.g., Ahtee et al., 2016; Glasnović Gracin \& Kuzle, 2018; Pehkonen et al., 2016). On the basis of the data from participant-produced drawings, two inventories were developed. These were then used as a window into students' perceptions of geometry and arithmetic classroom learning milieu from a social perspective. As outlined earlier, the drawings provided meaningful information that would not have been evident through simple interviews or observations (Ahtee et al., 2016). Since our model of classroom social climate is divided into subdimensions with accompanying scales to capture different aspects of the student's data, it also enables researchers to precisely capture the classroom social climate reflecting versatile behaviors, actions, situations, and experiences that were available in the participant-produced drawings. However, some of these can be combined into bigger entities, depending on the research interest, thus if the finegrained analysis is needed or not. For instance, subdimensions of the dimension Participation could be clustered in active and passive, if the focus is only on its nature, and not on different types of students' participation during the mathematics lessons.

The students' perceptions of the classroom social climate could only be considered complete with additional interpretation and discussion of the drawing by the participant. As Blumer (1969) noted, the analysis of drawings is understood as interpreting the meanings that the students had given to the situations and objects they had presented. Thus, in order to avoid the coder's own interpretation, not only analyst triangulation is needed, but also methodological triangulation such as participant-produced drawings (Kearney \& Hyle, 2004), allowing each student to 
interpret his or her own drawing, which consequently allowed an in-depth understanding of what the student had drawn. In the analysis presented in this paper, the students' drawings were combined with a semi-structured interview. This means that the research object (i.e., students) was approached from two methodological perspectives by using different approaches to capture the classroom social climate in mathematics teaching in elementary school. This has the advantage that the perspectives in the students' drawings on arithmetic and geometry teaching were reinforced by the verbal data in the form of an interview (Bland, 2012). Firstly, we can report that the semi-structured interview provided additional information, providing a more comprehensive picture of mathematics lessons. Using the interview guidelines, additional subdimensions were addressed in the domains associated with them. Consequently, through the interview questions, more information was obtained so that more subdimensions with accompanying scales could be identified in the corresponding domains in addition to the illustrated subdimensions. Secondly, it must be noted that there has shown to be some drawbacks in using drawings: some children had difficulties drawing, some did not like drawing, and some aspects could only be expressed in a limited way through drawing. In such cases, additional data sources (i.e., a semi-structured interview) is necessary (Kuzle \& Glasnović Gracin, 2020). Thirdly, interpretation of students' drawings has proven to be a challenging task since their analysis should be understood as interpreting the meanings that the students had given to presented situations and objects (Blumer, 1969). Thus, in order to avoid the coder's own interpretation, not only analyst triangulation is needed, but also methodologies, such as participant-produced drawings (Kearney \& Hyle, 2004), allowing each child to interpret his or her own drawing, which consequently allows an in-depth understanding of what the child had drawn.

The amount of researcher-imposed structure and its clarity on the drawing process is a determinant in what aspects are portrayed in the drawings. One can distinguish between different types of image representations (e.g., De Beni \& Pazzaglia, 1995), such as general, specific, and episodic. An image may be general referring to a concept without any reference to a particular example or to specific characteristics of the item (e.g., a table is described as a surface with four legs). On the other hand, one can have a specific image of a table, such as a classroom table. Thus, a specific image refers to a single, well-defined example of the concept without reference to a specific episode. Lastly, an episodic-autobiographical image refers to the occurrence of a single episode at a particular time and place in the subject's life 
connected to the concept (e.g., a student draws a successfully completed task during a mathematics lesson in the past). Most students' drawings in our study represented episodic-autobiographical images (De Beni \& Pazzaglia, 1995) illustrating the occurrence of a single episode (i.e., a geometry lesson or an arithmetic lesson) at a particular time and place in their mathematics class. Thus, giving students a concrete drawing assignment but with little structure allowed them to illustrate and communicate unique and personally significant experiences and avoided imposing a particular perspective on them.

Participant-produced drawings create a window into students' perceptions of mathematics classroom learning milieus from a social perspective, making them viable tools for teachers. Teachers are the most significant influencing factor in students' learning (Hattie, 2013); their attitude and willingness to teach determine the development of students' content-related and process-related competencies. Trickett and Moos (1973) already emphasized that teachers can learn a lot about their teaching through classroom climate instruments. Drawings offer an even greater potential for teachers to capture children's thoughts and perceptions (Anning, 1997; Anning \& Ring, 2004). Their use in the classroom could make students' perceptions and experiences of the teaching process more visible. For instance, the aspects of the classroom social climate model that occur less frequently may have played a subordinate role in classroom instruction. Thus, children's drawings and their interpretations are productive ways of promoting constructive dialogue about teaching and learning between students and their teachers, and in that sense help them plan and implement changes for future lessons (Anning, 1997; Anning \& Ring, 2004). This is paramount since characteristics of learning environments are powerful predictors of students' academic success (e.g., Evans et al., 2009).

The modified classroom social climate model emerging from the participantproduced drawings is independent of the mathematical content. The analytical tools that emerged from the participant-produced drawings with respect to geometry and arithmetic lessons showed great similarities. The only differences emerged in the description of some subscales pertaining to the "Interpersonal Relationship" category with the associated subdimensions "Participation" and "Responding" and subscales pertaining to the "Personal Growth" category with the associated subdimension "Teaching materials and tools". With respect to the latter, the differences were bigger since the teaching materials and tools differ greatly depending on the mathematical content area. Nevertheless, the modified model of the classroom social climate model 
emerging from the participant-produced drawings proved to be independent of the mathematics subject area (i.e., arithmetic and geometry). Thus, it is our opinion that - independent of the subject whose classroom social climate is in focus and independent of the different subject content areas - our classroom social climate model is viable and can be used for diverse qualitative inquiries in education in general.

\section{References}

Ahtee, M., Pehkonen, E., Laine, A., Näveri, L., Hannula, M. S., \& Tikkanen, P. (2016). Developing a method to determine teachers' and pupils' activities during a mathematics lesson. Teaching Mathematics and Computer Science, 14(1), 25-43. https://doi.org/10.5485/tmcs.2016.0414

Anning, A. (1997). Drawing out ideas: Graphicacy and young children. International Journal of Technology and Design Education, 7, 219-239.

Anning, A., \& Ring, K. (2004). Making sense of children's drawings. Open University Press.

Barlow, C. M., Jolley, R. P., \& Hallam, J. L. (2011). Drawings as memory aids: optimising the drawing method to facilitate young children's recall. Applied Cognitive Psychology, 25(3), 480-487. https://doi.org/10.1002/acp.1716

Bland, D. (2012). Analysing children's drawings: applied imagination. International Journal of Research \& Method in Education, 35(3), 235-242.

https://doi.org/10.1080/1743727x.2012.717432

Blumer, H. (1969). Symbolic interactionism. Perspective and method. Prentice Hall.

Bülter, H., \& Meyer, H. (2015). Unterrichtsklima als Determinante des Lernerfolgs [Teaching climate as a determinant of learning success]. In I. Leitz (Ed.), Motivation durch Beziehung (pp. 25-67). Springer Fachmedien.

Creswell, J. W., \& Miller, D. (2000). Determining validity in qualitative inquiry. Theory Into Practice, 39(3), 124-130. https://doi.org/10.1207/s15430421tip3903_2

De Beni, R., \& Pazzaglia, F. (1995). Memory for different kinds of mental images: Role of contextual and autobiographic variables. Neuropsychologia, 33, 1359-1371.

Eder, F. (2002). Unterrichtsklima und Unterrichtsqualität [Teaching climate and teaching quality]. Unterrichtswissenschaft: Zeitschrift für Lernforschung, 3O(3), 213-229.

Einarsdóttir, J. (2007). Research with children: methodological and ethical challenges. European Early Childhood Education Research Journal, 15(2), 197-211.

https://doi.org/10.1080/13502930701321477

Evans, I. M., Harvey, S. T., Buckley, L., \& Yan, E. (2009). Differentiating classroom climate concepts: academic, management, and emotional environments. Kotuitui: New Zealand Journal of Social Sciences Online, 4(2), 131-146. https://doi.org/10.1080/1177083x.2009.9522449

Fahlström, M., \& Sumpter, L. (2018). A model for the role of the physical environment in mathematics education. Nordic Studies in Mathematics Education, 23(1), 29-45.

Fisher, D. L., \& Fraser B. J. (1983a). Validity and use of the classroom environment scale. Educational Evaluation and Policy Analysis, 5(3), 261-271.

Fisher, D. L., \& Fraser B. J. (1983b). Use of classroom environment scale in investigating effects of psychosocial milieu on science students' outcomes. ERIC.

http://files.eric.ed.gov/fulltext/ED228062.pdf 
Fraser, B. J. (2012). Classroom environment. Routledge.

Fraser, B. J., \& Fisher, D. L. (1983). Development and validation of short forms of some instruments measuring student perceptions of actual and preferred classroom learning environment. Science Education Assessment Instruction, 11, 115-131.

https://doi.org/10.1002/sce.3730670114

Glasnović Gracin, D., \& Kuzle, A. (2018). Drawings as external representations of children's mathematical ideas and emotions in geometry lessons. Center for Educational Policy Studies Journal, 8(2), 31-53. https://doi.org/10.26529/cepsj.299

Harrison, L. J., Clarke, L., \& Ungerer, J. A. (2007). Children’s drawings provide a new perspective on teacher-child relationship quality and school adjustment. Early Childhood Research Quarterly, 22(1), 55-71. https://doi.org/10.1016/j.ecresq.2006.10.003

Hattie, J. (2013). Lernen sichtbar machen [Making learning visible]. Schneider Verlag Hohengehren.

Hill, M. (1997). Participatory research with children. Child and Family Social Work, 2, 171-183. https://doi.org/10.1046/j.1365-2206.1997.00056.x

Kearney, K., \& Hyle, A. (2004). Drawing out emotions: The use of participant-produced drawings in qualitative inquiry. Qualitative Research, 4(3), 361-383.

https://doi.org/10.1177/1468794104047234

Kuzle, A., \& Glasnović Gracin, D. (2020). Making sense of geometry education through the lens of fundamental ideas: An analysis of children's drawing. The Mathematics Educator, 29(1), 7-52.

Literat, I. (2013). "A pencil for your thoughts": Participatory drawing as a visual research method with children and youth. International Journal of Qualitative Methods, 12(1), 84-98. https://doi.org/10.1177/160940691301200143

Lodge, C. (2007). Regarding learning: Children's drawings of learning in the classroom. Learning Environments Research, 10, 145-156. https://doi.org/10.1007/s10984-007-9027-y

Malchiodi, C. A. (1998). Understanding children's drawings. Guilford Press.

Meyer, H. (2019). Was ist guter Unterricht? [What is good teaching?] (14th ed.). Cornelsen Verlag.

Moos, R. H., \& Moos, B. S. (1978). Classroom social climate and student absences and grades. Journal of Educational Psychology, 7o(2), 263-269.

OECD (2019). Education at a glance 2019: OECD indicators. OECD Publishing. https://doi.org/10.1787/f8d7880d-en

Patton, M. Q. (2002). Qualitative research and evaluation methods (3rd ed.). Sage.

Pehkonen, E., Ahtee, M., \& Laine, A. (2016). Pupils' drawings as a research tool in mathematical problem-solving lessons. In P. Felmer, E. Pehkonen, \& J. Kilpatrick (Eds.), Posing and solving mathematical problems. Advances and new perspectives (pp. 167-188). Springer. https://doi.org/10.1007/978-3-319-28023-3

Radatz, H., Rickmeyer, K., \& Freitag, W. (1991). Handbuch für den Geometrieunterricht an Grundschulen [Handbook for teaching geometry in elementary schools]. Schroedel.

Trickett, E. J., \& Moos, R. H. (1973). Social environment of junior high and high school classrooms. Journal of Educational Psychology, 65(1), 93-102.

Trickett, E. J., \& Quinlan, D. M. (1979). Three domains of classroom environment: Factor analysis of the classroom environment scale. American Journal of Community Psychology, 7(3), 279-291.

Veale, A. (2005). Creative methodologies in participatory research with children. In S. Greene \& D. Hogan (Eds.), Researching children's experience (pp. 253-273). Sage.

Wellman, H. M., Hollander, M., \& Schult, C. A. (1996). Young children's understanding of thought bubbles and of thoughts. Child Development, 67(3), 768-788.

https://doi.org/10.2307/1131860 